\title{
SLACKLINE: SAÚDE, AVENTURA E EMOÇÃO PARA OS IDOSOS.
}

\author{
Dimitri Wuo Pereira \\ Universidade Nove de Julho, São Paulo, São Paulo, Brasil \\ Juliana Teles Tavares \\ Universidade Nove de Julho, São Paulo, São Paulo, Brasil \\ Frank Shiguemitsu Suzuki \\ Universidade Nove de Julho, São Paulo, São Paulo, Brasil
}

\begin{abstract}
Resumo
Na tentativa de minimizar os processos degenerativos causados pelo envelhecimento percebe-se no slackline uma ferramenta com potencial para a melhoria da qualidade de vida da população idosa. $\mathrm{O}$ objetivo desse estudo foi analisar essa atividade em um grupo pertencente a um programa de atividade física orientada. A pesquisa descritiva utilizou como instrumentos: (1) diário de campo, (2) questionário (3) sistema de conversação e (4) teste de equilíbrio. Após as intervenções de slackline percebeu-se que ele fornece estímulos neuromotores interessantes para essa faixa etária, mas evidenciou-se que o aumento da autoconfiança, a motivação para realização da prática e maior inserção social desta população foram aspectos relevantes que justificam o tipo de intervenção.
\end{abstract}

Palavras Chave: Idosos. Slackline. Equilíbrio.

\section{Introdução}

O slackline é uma das modalidades de aventura que obteve grande número de adeptos nos últimos anos, pelo fácil aprendizado e pelo envolvimento com o lazer, podendo sendo praticado em qualquer ambiente (XAVIER, 2012). Ele consiste em equilibrar-se sobre uma fita de nylon com cinco centímetros de espessura que é estendida sobre bases de apoio (árvores e postes). Surgiu como forma de treinar o equilíbrio por escaladores e baseia-se na corda bamba circense (PEREIRA, 2013).

Essa atividade oferece desenvolvimento da força muscular de membros inferiores e melhoria do equilíbrio o que a torna um exercício funcional gerando benefícios à saúde (PEREIRA e MASCHIÃO, 2012).

Huber e Kleindl (2010) apontam que o treinamento do slackline pode auxiliar na recuperação do equilíbrio através das contrações musculares das articulações do joelho, tornozelo e quadril. Keller e col. (2012) perceberam que houve diminuição do reflexo de Hoffmann, em indivíduos treinados no slackline em comparação aos não treinados. O reflexo $\mathrm{H}$ ocorre no nervo tibial posterior gerando contrações involuntárias na musculatura da perna e dificultando o controle da estabilidade.

Uvinha (2001) afirma que essas práticas associam-se ao universo juvenil pela característica de desafio, confronto com o perigo e superação. Porém para o idoso essa atividade não costuma ser relacionada em um programa de exercícios, pois é potencialmente arriscada, e o idoso tem uma diminuição de força, flexibilidade, agilidade e percepção (MCARDLE, KATCH, KATCH, 2011), afastando este grupo de práticas com chance de quedas. Porém, os benefícios de andar sobre a fita sugerem a investigação dessa modalidade para melhoria da qualidade de vida das pessoas. Nesse aspecto Marinho (2003) aponta a 
aventura como uma possibilidade de resistência dos seres humanos às pressões sociais, valorizando a subjetividade como possibilidade de expressão e a coletividade como afirmação da alteridade.

O controle corporal obtido através de atividades motoras pode desempenhar um papel importante na autoestima de indivíduos idosos. A manutenção da saúde e do condicionamento físico contribui para o aumento da sensação de bem estar e satisfação pessoal, o que por sua vez contribuem para um envelhecimento com qualidade (SPIRDUSO, 2005).

Reforçam essa ideia, Cosme, Okuma e Mochizuki (2008): “[...] a prática da atividade física colabora para uma velhice saudável, diminuindo ou retardando as perdas inerentes ao processo do envelhecimento" (p. 45).

Porto Alegre e col. (2012) apontam que a prática de exercícios contribui significativamente com o aumento do equilíbrio em idosas, acentuando o valor da atividade física para essa faixa etária.

Justifica-se essa pesquisa pela escassez de investigações sobre o tema, e possibilidade do slackline prevenir um dos problemas mais graves à saúde do idoso, as quedas, pois segundo Maciel e Guerra (2005) as alterações de equilíbrio são fatores que levam a limitações graves na realização das atividades diárias. Além disso, há benefícios psíquicos e sociais que o andar sobre a fita desenvolve como a confiança, o autocontrole e a sociabilidade entre os praticantes (PEREIRA, 2013).

A observação da prática do slackline e a vivência dos pesquisadores com o tema sugerem que resultados positivos em relação ao equilíbrio e a força poderão ser obtidos com o grupo de idosos. Sendo assim, o objetivo desse estudo é analisar a prática de slackline em um grupo de idosos pertencentes ao programa de atividade física orientada.

\section{Método}

Definiu-se que a pesquisa qualitativa abrange os objetivos desejados, para obter informação dos sujeitos e interpretá-las a partir das referências bibliográficas disponíveis que embasam o assunto.

Um grupo de 34 idosas do PROSAMI (Programa de Saúde da Melhor Idade), que realizam atividade física orientada na Universidade Nove de Julho - SP participou desse estudo, que foi aprovado pelo Comitê de Ética da instituição, parecer número 394893. Todas assinaram o Termo de Consentimento Livre e Esclarecido (TCLE).

Três instrumentos utilizados para obter informações qualitativas das participantes durante sua vivência foram aplicados (GONZALEZ REY, 2005):

Diário de Campo - registro escrito das aulas em caderno feito pelos pesquisadores durante as práticas. Nesse instrumento observações e reflexões ajudavam a lembrar das situações vividas e promoviam interpretações sobre diversos aspectos do comportamento das participantes.

Questionário - com perguntas objetivas sobre a prática. Serviram para verificar a compreensão das participantes sobre essa prática e os benefícios que sentiam ao vivencia-la. O questionário ajudou a entender a intensidade, a variedade e a motivação proporcionados por esse exercício em relação as atividades realizadas pelo grupo. Também forneceu melhor compreensão sobre o exercício e a qualidade de vida dos sujeitos pesquisados. As perguntas elaboradas pelos pesquisadores foram: $\mathrm{O}$ que você mais gosta nas atividades desenvolvidas nesse grupo? Equilibrar-se no slackline sem auxílio é uma possibilidade real para você? Que atividades do dia a dia são difíceis de realizar? O que te dá medo na vida? No dia a dia o que te deixa alegre?

Sistema de Conversação - conversa em grupo com os participantes de forma aberta e direta, as opiniões eram livres e registradas em gravador digital, e algumas observações eram 
feitas em caderno, para posteriormente serem discutidas entre os pesquisadores obtendo informação pertinente ao estudo. Durante as conversas temas foram levantados pelos pesquisadores para gerar diálogo entre os sujeitos, foram abordados: Quais suas maiores dificuldades na prática do slackline? O que você sente quando realiza essa aula? Qual a importância dos professores nas atividades? O que pensa do futuro? Como foi seu passado? Como está a vida no presente? Como é fazer exercício para você?

O Diário de Campo foi preenchido durante toda a pesquisa. Os Questionários foram aplicados no início das sessões. O Sistema de Conversação aconteceu durante as práticas em pequenos grupos e ao final das mesmas com o grupo todo, em geral, ao final do dia, todos se reuniam para conversar e expressar suas opiniões sobre as vivências, seus sentimentos e seu desenvolvimento em relação ao slackline.

$\mathrm{O}$ quarto instrumento com objetivo de avaliar quantitativamente foi o Teste de Equilíbrio (adaptado de Gustafson e colaboradores, 2000), no qual o indivíduo deve permanecer em apoio unipodal com olhos abertos por até 30 segundos. A análise do teste segue a sugestão de Maciel e Guerra (2005) na qual o maior tempo nesse apoio em três tentativas é considerado, caso a pessoa atinja 21 segundos ou mais (sem tocar o solo com a outra perna) se considera que não há alteração no equilíbrio, valores inferiores a esse apontam alteração no equilíbrio, que significa que a pessoa tem dificuldades de manter a estabilidade por tempos prolongados. O Teste de Equilíbrio foi aplicado ao final das sessões.

Esse grupo realiza exercícios físicos orientados (musculação - segunda-feira e caminhada - quarta-feira), o slackline ocorreu sexta-feira. As rotinas duravam uma hora por dia. Os procedimentos de pesquisa foram aplicados apenas nos dias de exercícios sobre a fita, de fevereiro a novembro de 2013 e as aulas continham a seguinte organização:

- Alongamentos e relaxamentos realizados antes e depois das atividades de equilíbrio na fita.

- Exercícios de solo variados nos quais as participantes deveriam permanecer num tempo médio de um minuto cada exercício em pé (em um apoio, em dois apoios, com olhos fechados, com apoio na parte anterior dos pés, com apoio sobre os calcanhares, com pernas na posição anteroposterior, com semi flexão de joelhos em ângulos variados).

- Exercícios de andar no solo (sobre linhas no chão, sobre bancos, atravessando a trave de equilíbrio da ginástica, sobre colchões, sobre bastões de madeira, em degraus de plintos, sobre cordas).

- $\quad$ Desafio sobre a fita de slackline com cinco metros de distância sob uma altura de $30 \mathrm{~cm}$ do solo, com colchões de segurança e apoio dos professores nas mãos (permanecer parado na fita, ficar apoiado sobre um dos pés, flexionar os joelhos na fita com os pés em posição anteroposterior, andar na fita para frente, andar na fita para trás, atravessar a fita segurando uma corda de apoio sobre a cabeça, permanecer com os olhos fechados na fita).

Os exercícios foram organizados na forma de circuitos, isto é, enquanto algumas estavam na fita, outras estavam em exercícios de solo estáticos ou dinâmicos, em rodízio constante.

A análise dos dados baseou-se na filosofia hermenêutica que é a compreensão das experiências internas do indivíduo. Segundo Dilthey (1996 citado por SCHMIDT, 2014) é o processo de interpretação das objetivações empíricas da pessoa, por suas falas, expressões corporais, ou ideias apresentadas de forma escrita. Schmidt (2014) resume o modelo de compreensão hermenêutico como: a análise da compreensão das expressões; a natureza comum compartilhada entre autor e intérprete com o tema; a recriação das ideias do autor pelo intérprete; a compreensão do significado interno de um texto a partir das palavras.

\section{Resultados}


No diário de campo registrou-se que no início as idosas tinham pouco interesse na atividade, talvez por receio dos riscos de queda, ou pela novidade do tema. A aventura remete constantemente a noção do desconhecido, do inesperado, sendo assim, ela evoca o "por vir" (PEREIRA e ARMBRUST, 2010) e coloca em jogo as habilidades e percepções do indivíduo sobre suas capacidades de enfrentar os obstáculos do ambiente e sobre si mesmo. Apesar das inseguranças iniciais todas participavam e com o incentivo e supervisão dos pesquisadores, elas passaram a gostar da aula aos poucos, solicitando que não fosse mais retirada do programa de exercícios.

Percebeu-se que o medo de subir na fita foi desaparecendo e algumas quiseram se arriscar sem auxílio dos professores. Apesar disso, os professores mantiveram o cuidado e a proximidade com as idosas, segurando-as quando necessário, pois era imperativo evitar acidentes. De forma geral, pode se afirmar que as idosas não concluíram dez meses de prática com autonomia para andar na fita sem nenhuma supervisão, mas a relação com os professores foi fator decisivo para melhorar seu desempenho e apreciar o slackline como exercício.

Ao final das sessões algumas participantes puderam atravessar a fita sem apoio dos professores, mantendo apenas o acompanhamento próximo por critério de segurança. Deve-se levar em consideração que na prática do slackline o ajuste do equilíbrio ocorre com utilização dos membros superiores (HUBER e KLEINDL, 2010), portanto para que uma idosa possa realizar essa prática sem auxílio, deve ter controle sobre os movimentos dos braços, e tronco, do contrário é melhor manter sempre o professor apoiando um idoso. A queda na fita, mesmo em se tratando de altura inferior a 40 centímetros deve ser evitada, pois o histórico de osteoporose, artrite, pouca força muscular e outras limitações, que algumas traziam geravam uma responsabilidade extra nessa atividade para os pesquisadores.

As idosas relataram maior disposição em subir escadas. Ressalta-se que o grupo também realizou atividades aeróbias e musculação, portanto alguns resultados não representam apenas as contribuições deste exercício, mas há participação dessa atividade, porque além de ajudar a fortalecer os membros inferiores, ainda propicia melhor equilíbrio, através do controle dos movimentos dos pés sobre a fita.

No questionário aparecem informações pertinentes aos exercícios de solo, as participantes $\mathrm{n}^{\circ} 1,3,6,10,14,17,28$ e 32, disseram que "os exercícios no chão ajudam no equilíbrio sobre a fita". Essas afirmações confirmam a suspeita, de que a estratégia de ensino utilizada atingiu os objetivos de desenvolvimento motor esperado, isto é, combinar exercícios na fita e fora dela, para facilitar o aprendizado.

Outro destaque do questionário é a consideração da maioria das participantes de que a prática é de "moderada intensidade", provavelmente por que há pausas entre cada tentativa de travessia sobre a fita, permitindo recuperar-se do esforço exigido.

Uma das dificuldades apontadas por elas durante as conversas refere-se à concentração e manutenção de um ponto fixo durante o exercício, exigindo controle corporal e paciência. Esse fato demonstra a importância do slackline na determinação para um objetivo, fator importante para pessoas que com a idade vão perdendo capacidades e precisam enfrentar as dificuldades com persistência.

Segundo Rahal e Sguizzatto (2006), a manutenção de uma vida saudável depende muito do nível atividade física que o idoso realiza, então, espera-se com exercícios físicos, uma terceira idade mais prazerosa. $\mathrm{O}$ aumento do interesse pelo slackline durante as sessões demonstra uma associação possível entre prazer e exercício.

O teste de equilíbrio mostrou que $43 \%$ tiveram alteração de equilíbrio, isto é, não conseguem permanecer 21 segundos sobre um único apoio (GUSTAFSON e col. 2000). Isto indica necessidade de continuar com as atividades de estabilização, pois se percebeu que a 
musculatura dos membros inferiores precisa adquirir força e que os idosos devem desenvolver o controle muscular da região dos membros inferiores e quadril para evitar a perda de equilíbrio. Por ouro lado, $57 \%$ conseguem permanecer sobre um único apoio por um período maior do que 21 segundos, indicando que mais da metade do grupo já adquiriu condições de estabilização que podem impedir uma queda.

As idosas que atingiram 21 segundos ou mais apresentam mais força nos membros inferiores e o exercício sobre a fita contribui para esse incremento de forma específica, afinal durante a prática elas permanecem em contração isométrica. Os indivíduos que dominam a musculatura da região central do corpo e dos membros inferiores tem maior facilidade de impedir quedas, para Shumway-Cook e Woollacott (2003) a manutenção da estabilidade postural depende da capacidade de manter o centro de massa dentro dos limites da base de apoio.

Segundo Huber e Kleindl (2010) praticantes experientes não suportam uma oscilação de mais de dez centímetros do centro de massa, em relação à linha central do ponto de apoio, caindo da fita quando isso ocorre. Portanto, o controle postural e o uso da força dinâmica dos apoios dos pés sobre a fita devem ser constantes. A instabilidade da fita favorece a recuperação do equilíbrio, pois como aponta Floyd (2002) à manutenção da estabilidade depende da compensação à perturbação externa que o corpo está sofrendo quando se tenta andar sobre ela.

Os resultados apontam para a continuidade desse tipo de exercício, porque no slackline há necessidade de diminuir a altura do centro de gravidade em relação à base de apoio, favorecendo maiores contrações musculares dos membros inferiores, condições necessárias para manutenção do equilíbrio em pessoas com idade avançada.

\section{O PROSAMI}

Segundo o diário de campo, o ambiente das aulas apresentou grande interação entre os professores (pesquisadores e graduandos em Educação Física) e os idosos. O contato semanal entre eles evidenciou o convívio social e afetivo como fator decisivo para o aparecimento do sentimento de pertencimento ao grupo. Muitas idosas apontam que o professor é o grande incentivador e que sem eles não seria possível atingir os resultados, registrou-se que a relação inter-geracional foi positiva para o grupo.

O carinho, o sorriso, o abraço, a proximidade, a festa de fim de semestre, a troca de presentes no amigo secreto e o simples cumprimento com um beijo entre os jovens e as idosas fazem bem as participantes. Para as idosas encontrar os professores traz alegria, diverte e emociona. $\mathrm{O}$ grupo parece uma grande família, isso aumenta a aderência à prática e não se limita à aprendizagem dos objetos concretos relativos à saúde que o PROSAMI pode proporcionar, há também um "sentimento de ligação e responsabilidade com o outro" como constatou Lima (2003, p. 138) em pesquisa com essa faixa etária.

Segundo o questionário, para as participantes $\mathrm{n}^{\circ} 1,3,6,9,14,16$ e 23 o exercício preferido é a dança, apesar dessa atividade não ser contemplada como conteúdo, mas aparecer como estratégia em algumas sessões. O slackline é preferido apenas pelas participantes $\mathrm{n}^{\circ} 2$, 10 e 12. Esses dados demonstraram a necessidade de incluir as atividades rítmicas em grupos de idosas para elevar a motivação das participantes. Isto sugere que ouvir a opinião das senhoras a respeito de seus interesses em práticas corporais não deve se restringir ao aspecto motor dos protocolos de exercícios.

A esse respeito, Correia, Miranda e Velardi (2011) em pesquisas realizadas com idosos que realizaram um programa de atividade física colocam que o papel do professor de Educação Física deve contemplar o diálogo, a criticidade, a criatividade, encaminhando suas metas para o alcance da autonomia funcional e política em relação à saúde dos mesmos. 
Os dados do teste de equilíbrio sugerem a importância de exercícios com ênfase no equilíbrio para grupos de idosos, afinal o avanço da idade aumenta a propensão a quedas, que podem ser ocasionadas por degraus de escadas, pisos lisos, freadas do transporte coletivo, ou outros tantos acontecimentos do dia a dia, citados pelas mesmas como obstáculos. Há dificuldade, no entanto, de relacionar diretamente os resultados do exercício no slackline com a melhora específica na estabilidade, pois como apontaram Cosme, Okuma e Mochizuki (2008) sessões de exercícios com diferentes intervenções propostas por profissionais de Educação Física tornam difícil à comparação de resultados mesmo em testes padronizados. Além disso, as idosas realizavam outras práticas corporais que também contribuíram com melhorias funcionais.

Nas reflexões entre os pesquisadores apareceram aspectos relevantes. Acredita-se que a participação no grupo aumenta a habilidade motora e a capacidade funcional das idosas. Outro ponto importante é o fato do slackline aumentar a confiança dos idosos, o que afeta diretamente na sensação de liberdade que elas ganham com o exercício. Aspectos psicossociais colaboram nos benefícios adquiridos nessas aulas, como sugere Xavier (2012, p. 19) "nota-se no slackline um envolvimento social para além da atividade física".

No Diário de Campo os registros mostram que os pesquisadores concordaram que houve uma evolução multifatorial nas idosas, o que demonstra que elas ainda podem se desenvolver, aumentando sobremaneira sua autoestima e a perspectiva sobre a vida. Gerez (2006, p. 229) apontou em seu estudo com idosas que "[...] a necessidade de ser livre e aprender coisas novas, foram alguns dos aspectos citados espontaneamente pelos idosos para explicar o significado que o projeto teve em suas vidas". Isto reforça a ideia de que a atividade física deve ser compreendida como uma experiência de vida que pode ampliar os horizontes do ser humano lhe permitindo sonhar, planejar o futuro, acreditar em seu potencial e ser feliz.

Qualidade de Vida

$\mathrm{Na}$ Conversação, quando perguntadas sobre: O que dá medo? A principal resposta foi: "Doença" para as participantes nº 4, 6, 8, 9, 11, 27, 28, 30 e 32, isto é, 26,4\% do grupo. Essa preocupação estabelece uma relação direta com o exercício e sua necessidade para melhorar as condições de saúde das idosas. Sobre o exercício a participante $\mathrm{n}^{\circ} 19$ afirmou: "É bom para o organismo, corpo e mente, no exercício a gente esquece de tudo". A idosa $\mathrm{n}^{\mathrm{o}} 12$ disse: "Antes não fazia nada, só cuidava dos filhos, era sedentária. O exercício é maravilhoso, gosto mais do slackline e também faço exercícios em casa".

A violência e a família também foram lembradas, o que aponta para razões que vão além das capacidades pessoais para seus temores. O medo não se restringe aos aspectos que estão sob controle das participantes, mas também se refere a fatores ambientais e externos.

A prática de exercícios apesar de influenciar positivamente na saúde das idosas, não consegue eliminar seus temores sobre temas que as afligem no dia a dia. A doença e a violência alteram o comportamento das pessoas e a perda de capacidades que ocorre com o avanço da idade fragiliza a pessoa. Andar sobre a fita estimula e encoraja a superação de desafios psicológicos e físicos no praticante, apesar de não se tratar de uma profilaxia para o medo, sua execução no grupo permitiu a verbalização de sentimentos, mostrando que o tempo do exercício é também o momento de solidarizar-se e conhecer-se com mais profundidade a respeito da realidade de cada idosa do programa.

No Sistema de Conversação outros assuntos mostraram-se relevantes para as participantes. Quando questionadas sobre: $\mathrm{O}$ que as deixa alegre no dia a dia? Três dados apareceram com mais frequência: "trabalhar" (idosas n³, 6 e 9), "ver a família feliz" (idosas $\mathrm{n}^{\circ} 1,4,5,7$ e 15) e "fazer exercício" (idosas $n^{\circ} 2,10,11,12,17$ e 18) percebe-se que ter uma 
vida ativa e perceber que as pessoas que amam está bem é importante para quem dedicou a maior parte de sua vida aos familiares.

$\mathrm{Na}$ conversação quando relembradas sobre o passado, muitos relatos mostram passagens difíceis na vida das participantes, como: Participantes $\mathrm{n}^{\circ} 8,19$ e 29 apontaram a "falta de dinheiro", as idosas n³, 18, 23 e 24 falaram em "muito trabalho na infância", as idosas $n^{\circ} 6,12,20,21$ disseram que a "desistência dos estudos", já as idosas $n^{\circ} 2,7,10,22,30$ e 33 citaram os "desamores". Do futuro esperam ter saúde, conhecer e ver os netos bem, o que remete a percepção do corpo em boas condições (algumas relatam inclusive o câncer), para ver a felicidade naqueles que amam.

De forma geral, a subjetividade de cada uma, se expressou mais facilmente nas conversas e a experiência direta das participantes foi confrontada pelas interpretações das mesmas sobre os assuntos conversados, como por exemplo, a importância do exercício na vida, a importância do grupo de idosas no dia a dia, a relação da família na qualidade de vida de cada uma, entre outros temas debatidos.

A respeito dos efeitos do slackline na vida, relatou-se o "aumento da concentração" $\left(n^{\circ} 12,17,25\right)$, "facilidade em flexionar os joelhos" $\left(n^{\circ} 2,4,10\right.$ e 30$)$. A idosa $n^{\circ} 7$ relatou que o médico "elogiou os resultados dos exames clínicos". Novamente nota-se que os outros exercícios contribuem diretamente com essas respostas.

Os pesquisadores após cada sessão de exercícios em seus questionamentos, perguntavam sobre as dificuldades a respeito da aula realizada e as idosas eram enfáticas em afirmar que nada era difícil, mesmo quando dialogávamos sobre a incapacidade das mesmas em manter-se sobre a fita sem auxílio, diziam que eram capazes e que precisavam apenas de mais treinos.

Spirduso (2005) nos faz acreditar e combater estereótipos, delegando responsabilidades aos profissionais da saúde dizendo: "[...] em um momento de suas vidas, quando várias pessoas estão dizendo aos idosos que eles não podem, alguém, os profissionais, deveria dizer-lhes que eles podem".

Seguindo o mesmo raciocínio, Dias (2006) em seu estudo com atividades de aventura para idosos afirma:

A população idosa, se estimulada, seja em virtude da família, dos amigos, pelo contato direto com a natureza ou, simplesmente, devido a satisfazer sua curiosidade e ganhar nova experiência, trata essas atividades de aventura como um desafio em suas vidas, buscando superar ou conhecer seus próprios limites, assim como, a utilizam como meio para estabelecer a saúde e melhorar os níveis qualitativos de vida, agregando ainda mais importância, ao fato dessa busca pela vivência dessas atividades (104).

Há algumas hipóteses sobre essas afirmações:

- Elas se sentiam "empoderadas", como afirma Gerez (2006) a respeito do ideário da Promoção da Saúde, pela própria prática;

- Sentiam-se confiantes no amanhã, projetavam um futuro mais promissor;

- Tinham medo de que as aulas parassem e diziam que era fácil andar sobre o slackline para que as aulas não cessassem, mesmo não estando nos planos dos pesquisadores terminarem com o projeto.

Acredita-se que as perdas que tiveram durante a vida, lhes dá certa angústia sobre as coisas que gostam e que lhes trazem bem estar.

Nas conversas a maioria definiu-se como sedentária antes de começar no grupo, apesar de colocarem que andavam muito, que trabalharam na roça, ou com outros serviços braçais quando jovens. Algumas não eram sedentárias e sempre fizeram exercícios durante a vida e creditam ao grupo o prazer em manter as atividades motoras atualmente. 


\title{
Considerações finais
}

Em função do aumento da população idosa, percebe-se atualmente um crescimento significativo no incentivo a prática da atividade física com o intuito de minimizar os processos degenerativos associados ao envelhecimento.

Considerando a importância da inserção da população idosa na sociedade, porém de uma forma emancipatória e autônoma, tanto ao que tange a realização das tarefas da vida diária quanto ao poder de escolha de suas próprias práticas motoras, percebe-se que os programas de atividades físicas voltados para idosos devem estar compromissados em contemplar uma extensa variedade de práticas motoras.

Salienta-se durante o levantamento dos dados, a dificuldade de encontrar na literatura práticas associadas ao slackline e idosos, o que após este estudo nos dá parâmetros para que possamos avaliá-lo de uma forma positiva, como mais um exercício que pode auxiliar na qualidade de vida. Pode-se destacar dentre eles sentimentos expressos pelas participantes que valem a pena evidenciar, como por exemplo, a sensação de liberdade, e o aumento da confiança na realização de novas tarefas. Revelou-se que as idosas conseguirem aprender uma prática totalmente nova em uma idade, em que muitas acreditavam ser apenas o trajeto final da vida. O medo que essa prática fosse retirada do programa fornece indício do prazer que sentiam ao realizar neste grupo, as sessões de slackline.

Através do teste de equilíbrio, nota-se que o slackline oferece estímulos à coordenação motora e ao controle da musculatura postural. Segundo relatos das participantes o fato de conseguir atravessar, aumenta a habilidade motora e as "torna útil", expressão da qual sugere uma maior inserção social destas pessoas.

Acredita-se no potencial da prática sobre a fita em programas para idosos, pensando não somente nos benefícios do movimento para a saúde desta população, mas também no processo de busca para um novo significado ao envelhecimento, no qual é possível superar os medos, anseios e perdas através da motivação para novos desafios, aumentando assim a perspectiva destes indivíduos sobre a vida.

Sugerem-se mais estudos sobre o tema, afinal o caráter qualitativo da pesquisa pôde trazer à tona a subjetividade das participantes, apresentando suas singularidades como evidências do que a prática do slackline tem a oferecer para esse público. Não se pretende generalizar os resultados, devido às características do estudo, do grupo e das rotinas de exercício criadas para o aprendizado e que merecem mais tempo e avaliação dos pesquisadores, bem como testes que admitam o aumento da força ou a melhora do equilíbrio de idosos neste tipo de exercício.

\section{SLACKLINE: HEALTH, ADVENTURE AND EXCITEMENT FOR THE ELDERLY}

\begin{abstract}
In an attempt to minimize the degenerative process caused by aging is noticed in the slackline a tool with potential for improving the quality of the life of the elderly population. The aim of this study was to analyze this activity of a group belonging to a program of guided physical activity. The descriptive research used as instruments: (1) field diary, (2) questionnaire, (3) conversation system (4) one-step balance test. After the interventions of slackline it was noticed that it provides interesting neuromotor stimuli for this age group, but it became clear that the increase in self-confidence, motivation to carry
\end{abstract}


out the practice and greater social inclusion of this population were relevant aspects that justify the type of intervention.

Key words: Elderly. Slackline. Balance.

\section{SLACKLINE: SALUD, AVENTURA Y EMOCIÓN PARA LOS ANCIANOS}

\section{Resumen}

En un intento de minimizar los procesos degenerativos causados por el envejecimiento percibe el slackline con una herramienta potencial para mejorar la calidad de vida de la población de edad avanzada. El objetivo de este estudio fue analizar esta actividad en un grupo que pertenece a un programa de actividad física guiada. La investigación descriptiva utilizado como instrumentos: (1) diario (2) cuestionario (3) sistema de conversación y (4) prueba de equilibrio. Después de las intervenciones de slackline se observó que ofrece interesantes estímulos neuromotoras para este grupo de edad, pero se hizo evidente que el aumento de la confianza en sí mismo, la motivación para llevar a cabo la práctica y una mayor inclusión social de esta población fueron aspectos relevantes que justifican el tipo de intervención.

Palabras clave: Ancianos. Slackline. Equilibrio.

\section{Referências}

CORREIA, M. S.; MIRANDA, M. L. J.; VELARDI, M. A prática da educação física para idosos ancorada na pedagogia freireana: reflexões sobre uma experiência dialógicaproblematizadora. Movimento. Porto Alegre, v. 17, n. 04, p. 281-297, out/dez de 2011.

COSME, R. G.; OKUMA, S. S.; MOCHIZUKI, L. A capacidade funcional de idosos fisicamente independentes praticantes de atividade física. Revista Brasileira de Ciência e Movimento. v. 16, n. 1, p.: 39-46, 2008.

DIAS, V. K. A participação de idosos em atividades de aventura na natureza no âmbito do lazer: valores e significados. (120 f.) Dissertação de Mestrado em Ciências da Motricidade - Universidade Estadual Paulista. Campus Rio Claro. Rio Claro - SP, 2006.

GEREZ, A. G. A prática pedagógica em educação física para idosos e a educação em saúde na perspectiva da promoção da saúde: um olhar sobre o projeto sênior para a vida ativa - USJT. (270 f.). Dissertação de Mestrado em Educação Física na Promoção da Saúde. Universidade São Judas Tadeu. São Paulo, 2006.

GONZÁLEZ REY, F. L. Pesquisa qualitativa e subjetividade: os processos de construção da informação. São Paulo: Pioneira Thomson, 2005.

GUSTAFSON, A. S.; NOAKSSON, A. C. G.; KRONHED, A. C.G.; MOLLER, M. E.; MOLLER C. Changes in balance performance in physically active elderly people aged 73-80. Scandinavan Journal Rehabiltation Medical. v. 32: p. 168 - 172, 2000.

HUBER, P. e KLEINDL, R. A case study on balance recovery in slacklining. In: $28^{\circ}$ International Conference on Biomechanics in Sports. Human Performance Research Graz, University \& Medical University of Graz, Austria, 2010. ISSN: 1999-4168. 
KELLER, M.; PFUSTERSCHMIED, J.; BUCHECKER, M.; MÜLLER, E.; TAUBE, W. Improved postural control after slackline training is accompanied by reduced $H$-reflexes. Scandinavian Journal of Medicine \& Science in Sports. V. 22, N. 4, p. 471-477, 2012.

LIMA, A. M. M. Saúde e envelhecimento: o autocuidado como questão. (329 f.) Tese de Doutorado. Faculdade de Medicina da Universidade de São Paulo. São Paulo, 2003.

MACIEL, A. C. C. e GUERRA, R. O. Prevalência e fatores associados ao déficit de equilíbrio em idosos. Revista Brasileira de Ciência e Movimento. V. 13, N. 1, p. 37 - 44, 2005.

MCARDLE, W.; KATCH, F. I.; KATCH, V, L. Fisiologia do Exercício - Nutrição, exercício e desempenho humano. $7^{\text {a }}$ ed. Rio de Janeiro: Guanabara Koogan, 2011.

MARINHO, A. Da aceleração ao pânico de não fazer nada: corpos aventureiros como possibilidades de resistência. In: MARINHO, A.; BRUHNS, H. T. (Orgs.). Turismo, Lazer e Natureza. São Paulo: Manole, 2003, p.1-28.

OKUMA, S. S. O idoso e a atividade física: fundamentos e pesquisa. $5^{\text {a }}$ ed. Campinas: Papirus, 2009.

PEREIRA, B. As limitações do método científico: implicações para a educação física. Revista Paulista de Educação Física, São Paulo, v.12, n.2: 228-248, jul/dez, 1998.

PEREIRA, D. W; MASCHIÃO, J. M. Primeiros passos no slackline. EF Deportes - Revista Digital. Buenos Aires. Ano 17, n. 169, junho de 2012. Disponível em: <http://www.efdeportes.com/efd169/primeiros-passos-no-slackline.htm> Acesso em $10 / 12 / 2014$.

PEREIRA, D. W.; ARMBRUST, I. Pedagogia da Aventura: os esportes radicais de aventura e ação na escola. Jundiaí - SP: Fontoura, 2010.

PEREIRA, D. W. Vivências acadêmicas na educação física. Motrivivência. Ano 25, $\mathrm{n}^{\circ}$ 41, p. 223 - 233, dez. 2013.

POLI, J. J. C.; SILVA, A. O.; ALVES, A.; COSTA, C. G.; SILVA, G. R. M. Slackline na escola. In: VII CBAA - Congresso Brasileiro de Atividades de Aventura/ I CIAA Congresso Internacional de Atividades de Aventura: Tecnologias e Atividades de Aventura. Anais... Rio Claro/SP - Brasil. 6 a 8 de julho de 2012.

PORTO ALEGRE, R. S.; RIPKA, W. L.; MASCARENHAS, L. P. G.; AFONSO, C. A. Comparação dos níveis de mobilidade e equilíbrio em idosas praticantes e não praticantes de exercício físico. Estudos interdisciplinares sobre o envelhecimento. Porto Alegre - RS. v. 17, n. 2, p. $265-275,2012$.

RAHAL, M. A.; SGUIZZATTO, G. T.; Exercício Físico. In: CARVALHO FILHO, E.T.; NETTO. Geriatria fundamentos, clínica e terapêutica. 2a ed. São Paulo: Atheneu, 2006.

SCHMIDT, L. K. Hermenêutica. $3^{\text {a }}$ ed. Petrópolis - RJ: Vozes, 2014. (série Pensamento Moderno). 
SHUMMWAY-COOK, A.; WOOLLACOTT, M. H. Controle Motor - Teoria e Aplicações Práticas. $2^{\mathrm{a}}$ ed. Barueri - SP: Manole, 2003.

SPIRDUSO, W. W. Dimensões físicas do envelhecimento. Barueri - SP: Manole, 2005.

FLOYD, R. T. Manual de Cinesiologia Estrutural. 14ª ed. Barueri - SP: Manole, 2002.

UVINHA, R. R. Juventude lazer e esportes radicais. São Paulo, 2001.

XAVIER, G. C. Slackline em Porto Alegre - configurações da prática. Trabalho de conclusão de curso (63 f.). Universidade Federal do Rio Grande do Sul. Porto Alegre - R.S., 2012.

Recebido em: 07/06/2015

Revisado em: $14 / 12 / 2015$

Aprovado em: 11/05/2016

Endereço para correspondência:

dimitri.wuo@terra.com.br

Dimitri Wuo Pereira

Universidade Nove de Julho, Unidade Vila Maria

Rua Guaranésia, 425

Vila Maria

02112-000 - São Paulo, SP - Brasil 